\title{
Entrepreneurial Philanthropy Partnerships: Aligning Leadership, Strategy, and Culture
}

\author{
Jos Rath ${ }^{1}$ \\ ${ }^{1}$ Faculty of Social Sciences, VU University Amsterdam, Netherlands \\ Contact: Jos Rath, Faculty of Social Sciences, VU University Amsterdam, Netherlands. E-mail: \\ j.rath@rathgroup.com
}

Received: March 31, 2018

doi:10.5539/ijbm.v13n6p195

\begin{abstract}
There is increasing recognition that an entrepreneurial philanthropy partnership (EPP) has become a modus operandi for non-profit organisations and for-profit companies, aligning their interactions according to societal expectations. While these partnerships offer many advantages in principle, there is little consensus by academics and practitioners on what it presents for action, and its practice varies. The purpose of this article is to address the characteristics of EPPs that are associated with its establishment and with maintaining the continuous dialogue of tacit and explicit know-how. Therefore, a theoretical Entrepreneurial Philanthropy Alignment Model has been developed and is empirically tested in the context of existing EPPs in The Netherlands. The model may inform continuing theory building and practical experimentation to refine defining the amplitude of partnership practice, and to enhance the responsiveness to partners' expectations of an EPP.
\end{abstract}

Keywords: entrepreneurial philanthropy partnership, alignment, societal change, impact

\section{Introduction}

In today's increasingly complex world, both non-profits and companies compete for the attention of many stakeholders like investors, donors, customers, suppliers, civil servants, communities and employees. Both make strategic decisions about the level and nature of (financial) resources they will devote to reach their goals. The formation of an EPP between them can be seen as a pursuit of opposite attracting forces to tackle pressing societal issues that exceed the coping capacities of the individual actors (Maclean et al., 2012). It has been argued there are specific conditions under which a robust partnership is likely to emerge (Mohr \& Spekman, 1994). Engaged philanthropreneurs (PHs) may not have the fundamental motivation, legitimacy, access or expertise to tackle these societal issues alone, while the senior executives (SEs) of non-profit organisations may lack the desired budget, knowledge or operational efficiency. Therefore, many non-profits view an EPP as a necessary strategy to co-create shared value (Austin \& Seitanidi, 2014), especially since a retreating government and a growing competition for financial resources within the sector generates external pressures for non-profit organisations (Young, 2000). In addition, many non-profits look to EPPs in the belief that market based revenues can be easier to grow and more resilient than traditional philanthropic funding (Dees, 1998). The drive to become more entrepreneurial-oriented, however, may hold some dangers for non-profits. In the best circumstances, non-profits might face operational and cultural challenges in the pursuit of entrepreneurial philanthropy. In the worst, such a drive can undercut an organisation's social mission (Shaw et al., 2013). Despite all restrictions, the sustainable solving of complex societal problems calls for innovative cross-sector partnerships that combines the expertise and resources of several sectors (Stadtler, 2011). These partnerships provide an interesting setting in which to explore how societal efforts in companies are managed in the crossfire of societal and economic interests, since any misalignment may provoke negative feedback from the partners if it is at the expense of the partnership's societal interests (Berger et al., 2004). The goal of the research reported in this paper is to explore and understand a developed theoretical Entrepreneurial Philanthropy Alignment Model in its daily practice among Dutch senior executives of non-profit organisations and their entrepreneurial business partners.

\section{Central Question}

An EPP can be described as a purposive strategic arrangement between a PH and an SE who share agreed goals, acknowledge mutual business principles and a strive for mutual -but different- sustainable returns. Such an EPP 
can be attractive to produce societal, organisational, and/or individual impact, whereas the distribution of benefits depends on the cognitive frames held by the partnership participants. Despite the growing interest of both PHs and SEs in these partnerships, there are indications there is some resistance to installing and maintaining them (Mitchell \& Sparke, 2016). The potential for a realised societal change through EPPs does not come without risk since research has shown that the traditional intercompany partnerships have a modest $50 \%$ success rate (Gonzalez, 2001). Partnerships convey the impression of failure due to the confusion of tongues that might result in insufficient leadership commitment, lack of a formal strategy, and a cultural mismatch (Weiss et al., 2002). These hurdles can be further exacerbated in EPPs by complications such as undefined roles and responsibilities, poorly aligned capabilities, and hidden cultural differences. A structured approach to managing these risks seems essential, given the large investment of time and resources required to effectively manage EPP. Prescriptions for the formation of such EPPs often overlook the drawbacks of such relationships in the longer term and tend to conflate partnership processes with partnership outcomes. What causes this? To answer this question it requires an understanding of an EPP as a cross-cultural phenomenon, rather than as a modern management technique. An EPP appears to be a set of leadership tools, strategy concepts, as well as a set of cultural language games, all of which have their own dynamic and characteristic indicators.

The ability of both PHs and SEs to develop the required attitude, and a mutual understanding to build an EPP was theoretically modelled as (Figure 1.) 'Entrepreneurial Philanthropy Alignment Model' (EPAM), (Rath \& Schuyt, 2017).

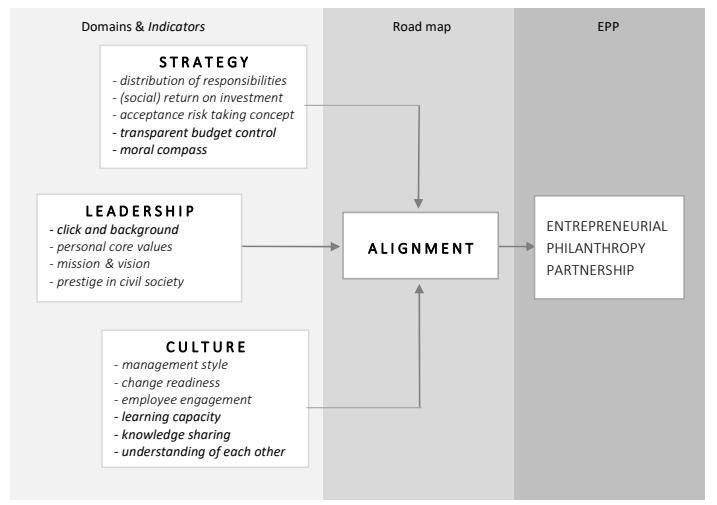

Figure 1. Theoretical entrepreneurial philanthropy alignment model (EPAM)

The EPAM is based on management theory and an observational view of the attitude and behaviour of both PHs and SEs in the process of partnering (Vicere, 2010; Kaplan \& Norton, 2006; Parmentier 2010). The model was developed to provide a better insight into the establishment of EPPs, as a partnership between a PH and an SE seem to be a complex paradox, involving individuals interacting at many organisational levels within the partners' organisations (Drucker, 2006). The theoretical model enables to ask PHs and SEs compelling questions and determine key decision points, to understand their roles more effectively, and to improve the establishment of an EPP. Specific domains were explored because they might provide indicators for the development of alignment, since in the process of partnering achieving alignment seems to be a concern for both the PHs and SEs involved (Murphy \& Bendell, 1999).

The EPAM includes three distinctive domains and a series of indicators which suggest a program to alignment that indicates to be a road map for establishing an EPP (Rath \& Schuyt, 2017). Essentially, a practical understanding of the EPP process will focus on its societal impact objectives, these objectives can lead to further learning and strategic action, what might deepen an understanding of the partnership processes involved (Patton et al., 2015). This circle of practice is what makes a theoretical model constructive and makes an EPP effectively theory-based. Consequently, the primary research question is formulated as follows: Can the EPAM determine whether or not an EPP between an philanthropreneur (and his/her company), and the senior executive of a non-profit will be established? The secondary research questions focus on several characteristics of the model. The interaction between the defined domains indicates that the information needed to assess expected partnership value is dispersed throughout the partnership organisation and may be difficult to aggregate in a meaningful way (Demetriou et. al, 2006). This article examines the theory-practice connection at the level of an 
EPP, whereas the theoretical EPAM is to guide the research systematically and comprehensively to examine how alignment between strategic rhetoric and practical reality leads to for-profit and non-profit partnership opportunities.

\section{Model and Hypotheses}

The theoretical EPAM is a continuation of studies performed in 2014 and 2015 by Rath and Schuyt, who thought about how these EPPs might develop over time. The defined research questions will be operationalised through a set of seven hypotheses, that specify the assumed relationships between the selected domains and indicators as independent variables. Similarly, the selected intermediating variable of alignment is used to contextualise its influence on the data studied. The constructs are explained and placed in relation to the EPAM. An overview of the relationships between the defined research questions and the hypotheses are illustrated in Figure 2.

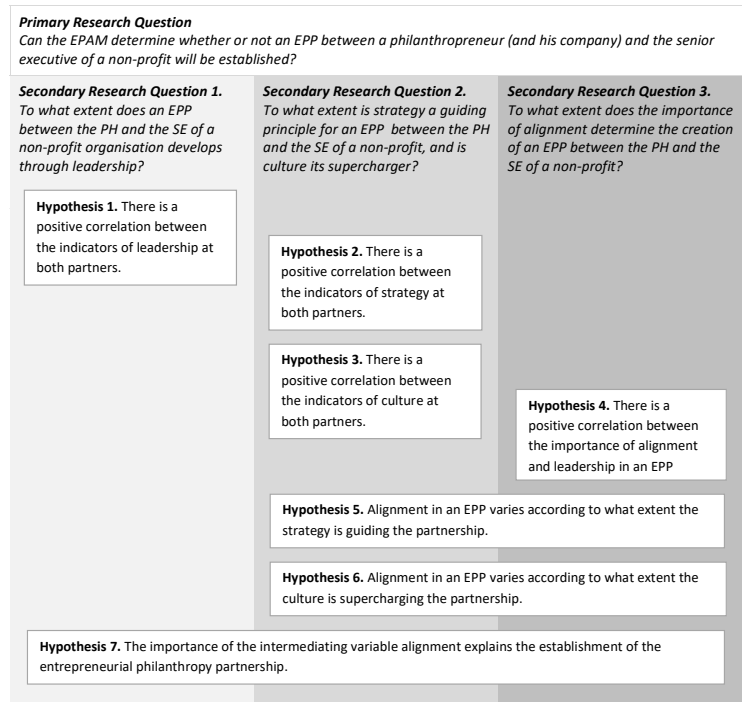

Figure 2. Overview of the hypotheses in relation to the research questions

The seven hypotheses were qualitatively tested in The Netherlands among the leaders of non-profit organisations and their entrepreneurial partners, as dimensions of importance whether or not to establish an EPP.

\section{Methodology}

The proposed methodology relies on qualitative research techniques to gather organisational behaviour knowledge about the development of an EPP. Qualitative methodology seems an appropriate strategy because empirical research in this area is at an early stage, the occurrence is complex and an EPP is likely to have both economic and symbolic components that may be difficult to capture with other methodologies (Siltaoja, 2006). In order to develop a structured, strategic approach to successfully engaging partners, representatives from organisations that exhibit partnership practices were selected. The sampling frame consisted of 481 non-profit organisations registered at the Dutch Central Bureau on Fundraising (Centraal Bureau Fondsenwerving) and candidates for interview were identified through research and discussions with opinion leaders of the sector. Within the research sample, a selection was made of senior executives of non-profit organisations that already have experience with EPPs. To investigate a small population of expert opinions, purposive sampling was used based on the selection of information-rich cases through maximum-variation sampling, to act as a validation of expertise and therefore improves content validity. The sample includes variations in societal category, budget, and level of experience with partnerships. Ten senior executives of non-profit organisations were interviewed, who were also willing to give an introduction to the responsible philanthropreneur/senior executive of one of their EPPs. In total, the 20 interviewees were partnership leads with first-hand knowledge of their organisation's partnering activities.

The data were collected by means of a series of semi-structured interviews designed to systematically capture the embedded knowledge of the partnership from two types of key informants - SEs from non-profit organisations and PHs. The non-profit executives provided a context as 'human-change agents' while the business executives provided a context from their entrepreneurial principles. A personal typology of each executive was made, based 
on their own perspectives on leadership (Trevisiani, 2016), strategy (Mintzberg, 1987) and culture (Handy, 1993). The results are documented as Figure 3.

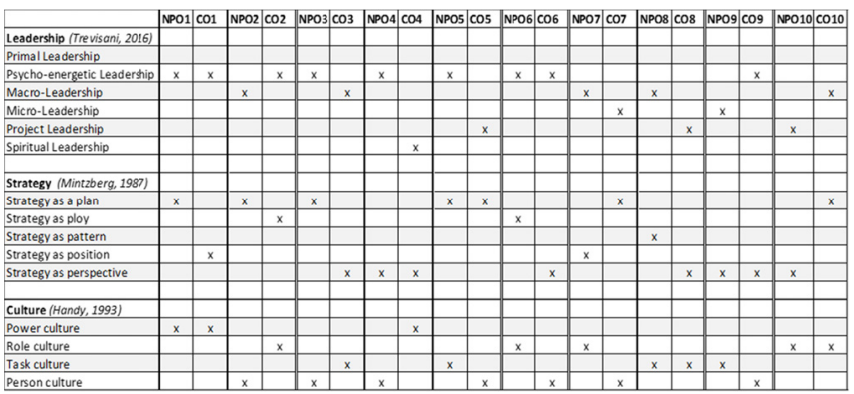

Figure 3. Typology interviewees

The questionnaire consisted of 49 items which were obtained from the literature review (Rath \& Schuyt, 2015), and qualitative testing of the indicators among EPP experience experts (Rath \& Schuyt, 2015). The selected indicators and were grouped into themes around leadership, incorporating partnerships into the organisation's strategy, communicating the cultural values of engaging the staff, and the process of alignment. The data derived from the interviews were used to identify the relative importance of each of the three domains: leadership, strategy, and culture and what their effect was on the process of alignment within the partnership.

One problem with the qualitative approach is that the results consist of non-standardised data, which require the researcher to classify them into specific categories for meaningful analysis, and can only be conducted using conceptualisation (Saunders et al., 2000). The concept of mixed methods research has been carried out, where explicitly the qualitative and quantitative aspects of study were combined (Johnson \& Onwuegbuzie, 2004). The limited number of observations will ultimately dictate the statistical procedures to be used in processing the data, whereby, based on the context of this pilot study and the concern of not being able not to measure interesting indications, the level of $10 \%$ significance was chosen (Stigler, 2008). The data will therefore have more meaning once interpreted according to the applicable Likert scale for this study, to determine a certain strength of attitude or behaviour. Respondents were required to indicate the degree of importance of each of a series of statements about the selected indicators within the three domains. The measurement by the researcher contains five response categories for each scale item ranging from 'very important' to 'not important', to understanding the EPP world and so constructing the methodology. To examine the answer of each statement, a closed-ended question was asked whether the described process was officially formalised within the organisation of the partnership process. The Likert-scale methodology was best suited to analysing and interpreting these data, as it aimed to establish the highest and lowest scores assigned to the variables by the respondents in terms of the importance and effectiveness of their leadership, strategy, and culture, and how important they felt these were for the process of alignment. Control questions were included to determine if the opinion of the interviewees was confirmed by an formal operational management policy.

As part of theory-building, also methodological expert intuition through observation, feedback, and iteration were required for valid methods of investigation to create a workable professional practice (Kahneman \& Klein, 2009). The cognition found might be context-sensitive because it consists of responsiveness to multiple possibilities for action provided by surroundings. Therefore, the expert intuition can improve the decision making process what might be important when there's restricted evidence for upfront research decisions that relies on theoretical evaluation. From this perspective, three independent domains (leadership, strategy and culture) and the intermediating variable (alignment) related to a qualitative dependent variable (EPP), which may or may not be qualitative, are used to produce multivariate analogues. The dependent variable in the analysis measures whether a PH and an SE will reach an EPP though the alignment process of their leadership, strategy and culture.

The collected data were modelled using linear- and ordered logistic regression, because both methods will yield similar, though not identical, inferences. In linear regression, the dependent variable is continuous and can have any one of an infinite number of possible values. In ordered logistic regression, the dependent variable has only a limited number of ordinal, positive possible values (Mood, 2010). Therefore, the statistical technique implemented for this study was the ordered logistic regression used to estimate the probability distribution of partnership outcome and served to determine the EPAM. The output not only provided input for the rating of the 
domains but quantified the uncertainty surrounding the measure by providing the variance of the distribution as well. The interpretations of probability and the odds that derive from this model seem somewhat intuitive, and ordered logistic regression allows nonlinear relationships between independent and dependent variables. The ordered logistic model seems a valuable predictor of the relations in the dataset, although the number of observations was relatively small. Validation also demonstrated that the ordered logistic model was accurate in evaluating the various hypothesis, and gave insights in determining the intermediating factor of alignment. The applied linear regression estimators are more effective than those obtained by an equation-by-equation application (Hayes \& Montoya, 2017). This might be adequate when the independent variables in the diverse comparisons are not highly correlated, and if disturbance terms are indeed highly correlated, by which all regression equation coefficient vectors seem equal.

Some of the hypothesis however, are not a formal causation therefore, correlations between the PHs and the SEs for the subjects in the hypothesis were studied and calculated with the Spearman's rank correlation coefficient. This statistical test is a nonparametric measure of the strength and direction of association that exists between two variables measured in an ordinal scale, and is used for ordinal variables that has failed the assumptions necessary for conducting the Pearson's correlation. It is also worth noting that a Spearman's correlation is also not very sensitive to outliers, what means that valid results can be obtained from using this test in the situation there are outliers in the data. Although measures of interpretation relating to texts differ from those of statistical analysis, because of the various data used and questions to be answered, the underlying assumptions are much identical. An intuitively meaningful expert understanding makes it possible to communicate better about the research results and to comprehend and critically evaluate the conclusions. This approach also determined a certain distance, which indicated the gaps between respondents' perceptions of the current state and patterns of their behaviour in leadership, strategy and culture, and the relative importance of such behaviour for the effects of alignment in the partnership. An EPP seems a dynamic process evolving over time, and like any relationship it takes much time to evolve (Austin \& Seitanidi, 2012). The analysis presented concentrates on information contained from the interviews and has been guided by the theoretical model relating to entrepreneurial philanthropy partnership.

\section{Results}

This study contains a theoretical model EPAM, a series of tentative hypotheses, a sample of data, and the goal of learning about the phenomena from practical EPP observations. The data used to investigate the hypotheses is to motivate the analysis of each of the statistical models presented. This linkage between the process that is thought to have generated the data and the statistical model, is progressed from investigating the possibilities for determining the location and scale parameters for a population from a sample of observations, to investigating a complex simultaneous system of structural equations under general stochastic assumptions.

\subsection{Indicators of Leadership}

The first objective was to identify correlations between the indicators of leadership at PHs and SEs, in order to accomplish the aimed EPP. This objective led to the development of hypothesis 1: There is a positive correlation between the indicators of leadership at both partners. In this hypothesis the context is not a formal causation; therefore only the correlations between the PHs and the SEs for the subjects in the hypothesis were studied and calculated. The importance of each indicator of leadership was measured on a Spearman's rank correlation, and suggested the following correlations (Table 1):

Table 1. Spearman correlation coefficients for multiple questions between the senior executive of a non-profit and the philanthropreneur as their respective business partner (Significant result at the $10 \%$ significance level is in bold.)

\begin{tabular}{lll}
\hline & Spearman correlation & p-value \\
\hline Q1. Importance of an instant connection / click & 0.46 & 0.18 \\
Q3. Importance of a mutual background (study, career etc.) & 0.49 & 0.15 \\
Q5. Importance of shared personal core values & -0.30 & 0.40 \\
Q7. Importance of mutual mission \& vision on civil society & -0.35 & 0.32 \\
Q9. Importance of effects of prestige & $\mathbf{0 . 5 8}$ & 0.08 \\
\hline
\end{tabular}

The correlations of the importance of the indicators of leadership in an EPP revealed that there were no significant correlations between four of five indicators; thereby, little evidence was found that hypothesis 1 was supported by the results. However, there was a positive correlation in the effects of prestige, illustrating that what 
a $\mathrm{PH}$ indicates the effects of prestige as important, the SE has a mutual opinion and vice versa. The other four indicators seemed to be weak predictors of how leadership effects the EPP, but the implications were not straightforward. It was reasonable to assume that these correlations of leadership indicators were invisible due to the relative small number of observations analysed. In the context of this paper, the following questions assisted in demonstrating the formulation of hypothesis 1 :

- Was there an instant 'click' (Q2) - Sixteen out of 20 respondents responded with 'Yes';

- Was there a mutual background (Q4) - Seventeen out of 20 respondents answered with 'No';

- $\quad$ Are there shared personal core values (Q6) - Fifteen out of 20 respondents answered with 'Yes';

- Is there a mutual mission and vision (Q8) - Sixteen out of 20 respondents responded with 'No';

- $\quad$ Are there effects of prestige (Q10) - Ten out of 20 respondents answered with 'Yes'.

The results of the correlations between the indicators of leadership in an EPP emphasised leadership as activity and interaction at the board level of an EPP, and indicated one single interaction, the personal 'click' as very important to mobilising jointly an ambitious societal effort, next to the perception for what personal core values stand. The correlations suggested that these indicators, including the effects of prestige, are influenced by the beliefs, attitudes and actions of both partners when they have the ambition to establish an EPP. The correlations provided are possible evidence of what can be described as good practice within the partners of an EPP. Consistency in the answers also revealed that several of these partnerships that were researched had never created conditions to formalise the partnership's vison and mission and therefore seemed a weak predictor in this model.

It has been argued both partners faced a complex partnership challenge regarding the necessity of connecting and integrating two important yet conflicting forces: Diversity and interdependence, reflecting the constant tension between the self and others (Oliver, 1990). In this dynamic interaction, it was believed increasingly essential to establish an EPP to foster change by understanding the effects of high quality connections and to have much patience along the partnership process to address the mutual ambition to solve complex societal problems. Each of the leaders work with and influence different teams and different individuals, having no predetermined methods, and their leadership in an EPP should maintain that outsider's perspective (Suen, 2005). This 'insider-outsider perspective' requires a culture of coordination and inclusion and helps PHs and SEs to explore new routes to an effective EPP. Leadership should foster this culture through endorsing partnering as an organisation-wide priority and by promoting a solutions-seeking mentality (Day \& Antonakis, 2012). Creating societal change and demonstrate the prestige derived from it to stakeholders in the civil society seems to mean taking leadership and releasing initiative, driving and motivating the staff to create an atmosphere of cooperation. It concerns relinquishing the desire to control and, allowing the strengthening influence of the for-profit world to be felt, without distracting from the substantive qualities of the non-profit world. It is suggested that most leadership indicators are important dimensions when prioritising the cooperation of EPs and SEs, even when the transformational considerations of an EPP should be forgotten. On a more conceptual level, the indicators and associations with other variables here presented can be used to identify linking patterns of leadership for the establishment of EPPs.

\subsection{Indicators of Strategy}

The objective here was to identify correlations between the indicators of strategy at PHs and SEs in order to establish the aimed EPP. This objective led to the formation of hypothesis 2: There is a positive correlation between the indicators of strategy at both partners. In this hypothesis, the context is not a formal causation; therefore, only the correlations between the PHs and the SEs for the subjects in the hypothesis were studied and calculated. The importance of each indicator of strategy was measured on a Spearman's rank correlation, and suggested the following correlations (Table 2):

Table 2. Spearman correlation coefficients for multiple questions between the senior executive of a non-profit and the philanthropreneur as their respective business partner (Significant results at the $10 \%$ significance level are in bold)

\begin{tabular}{lll}
\hline & Spearman correlation & p-value \\
\hline $\begin{array}{l}\text { Q15. Importance of strict usage of internal procedures in } \\
\text { partnership }\end{array}$ & $\mathbf{0 . 7 5} 0.01$ \\
Q17. Importance of measuring the return on investment & $\mathbf{0 . 6 0}$ & 0.06 \\
\hline
\end{tabular}


For importance of transparency in budget control (Q21) and having an inner moral compass (Q23): there was insufficient variation in the data (this indicator was very / important to all interviewees) to determine a correlation. Therefore the answers to the questions provide evidence to support hypothesis 2, which was therefore unable to be rejected. This study identified support for normative societal ideals within the investigated EPPs; however, organisational particularity also pervaded the deployment of strategic information. Therefore, EPP strategy development appears to be an iterative process, involving continual assessment and refinement. It has been argued there is a wide variety in the form and nature of strategies within these EPPs. The PHs tend to focus on the structure and formality of strategic activities and call for a balance of transparent financial and non-financial information to support the strategic processes, while a large number of SEs specifically concentrates on the use of strategic information regarding the implementation of their mission, following their own moral compass (Babiak \& Thibault, 2007). It was noted that most interviewees saw their EPP as strategically critical to their own organisation. Unsuccessful partnerships fritter away time and can damage relationships, which ultimately lead to the loss of reputation, people and money. PHs and SEs suggest engaging with and shaping initial strategies in order to understand and can take moral ownership of the program objectives. Both partners want to experience that the benefits of their relationship are reciprocal (Rumsey \& White, 2009). Collaboration within an EPP should be cooperative; it is expected to be effective if both partners pursue related objectives, share a common strategy, and are comparable members in the EPP organisation. Strategy in this context is not a 'where to' it is also a 'how to' and therefore seems to represent a manner in which to guide EPP aspirations that are based on a combination of indicators, and dialogue amongst PHs and SEs. An EPP appears to be a challenging way for PHs to share a compatible strategy to balance their economic and symbolic goals with the partnership's societal interests, while SEs are confronted with how they can strike a balance between their mission and the shared partnership goals. The notion of ownership among PHs and SEs is often used in this situation to describe the emotional binding of both partner organisations and all the staff involved, therefore an EPP should be able to bring together different groups of talented people in cooperative action as well as in cooperative efforts to effect a measurable social return on investment. The achievement of the selected strategy suggests a critical dependence on the leadership qualities of the involved PHs and SEs.

\subsection{Indicators of Culture}

The third objective was to identify correlations between the indicators of culture at PHs and SEs in order to establish the aimed EPP. Hypothesis 3 derived therefrom is as follows: There is a positive correlation between the indicators of culture at both partners. In this hypothesis the context is also not a formal causation; therefore, only the correlations between the PHs and the SEs for the subjects in the hypothesis were studied and calculated. The importance of each indicator of culture was measured using the Spearman's rank correlation coefficient (Table 3).

Table 3. Spearman correlation coefficients for multiple questions between the senior executive of a non-profit and the philanthropreneur as their respective business partner. (Significant results at the $10 \%$ significance level are in bold)

\begin{tabular}{lll}
\hline & Spearman correlation & p-value \\
\hline Q30. Importance of correlated management styles & -0.04 & 0.90 \\
$\begin{array}{l}\text { Q32. Importance of how prepared and able employees are for } \\
\text { change }\end{array}$ & -0.06 & 0.87 \\
Q34. Importance of stimulating the effort of employees & 0.23 & 0.53 \\
Q36. Importance of learning capacity of employees & -0.03 & 0.94 \\
Q38. Importance of stimulating knowledge sharing & 0.10 & 0.78 \\
Q40. Importance of gaining understanding of each other & 0.39 & 0.26 \\
\hline
\end{tabular}

The results of the correlations between the indicators of culture supported the paradigm that there are no significant correlations between any of the variables; therefore hypothesis 3 was rejected. These results indicate that a common perspective of the culture of a partnership can be an important predictor of its engagement in a feasible EPP. Both partners must create a management style that enforce cultural beliefs, which must lead partnership team members to proactively take decisive action to achieve specific results (Schein, 2010). It was mentioned that focused communication to engage the partnership staff about the desired changes in the culture, was a good practice to create alignment in an EPP. Initiating and operating an EPP may be a subtle activity 
requiring a leadership style that is comprehensive and can work with different cultures in varying organisations, addressing their questions. Expecting an EPP to have integrated its two cultures, and their various subcultures within a brief time-frame seems, however, unrealistic. Making such partnerships more sustainable often depends on whether the partners' cultures have the learning capacity to bridge their differences and to integrate (Connor \& Clawson, 2004). It has been argued that aligning cultures require the expenditure of much time and energy in understanding each other, regarding what each partner is supposed to be doing and why. This is interdependent with both the rational and emotional buy-in to the shared societal vision. As the main task of partnerships is to identify ways in which organisations - with their different tasks, responsibilities and approaches - can co-operate in dynamic societies, it has been said that it is essential to adopt a culture of working accordingly to supercharge the partnership. Thus, a stable framework is necessary; in contrast, a certain degree of flexibility is required to allow for necessary changes and adjustments. PHs and SEs are the critical architects, and require, first and foremost, a deep understanding of cultures, and, second, an ability to pragmatically apply that understanding. In addition, it has been stated that ongoing internal communication and dialogue is required among the partners for there to be a maximum knowledge sharing by all involved (Porter \& Kramer, 2006). Relatedly, there were questions of what to communicate about an EPP to external stakeholders. It was mentioned that this could breed loyalty, help to improve the partnership reputation and thus benefit the societal impact. However, it was also emphasised that it was better to first obtain results, rather than to communicate about them. This had encouraged different EPPs to have a policy of very limited external communication.

\subsection{Leadership, Alignment and Partnership}

The objective here was to develop a leadership driven approach to EPPs, to make both partners individually effective, and collectively cohesive, so that they experience the importance of alignment in achieving the desired partnership. This objective led to the development of hypothesis 4: There is a positive correlation between the importance of alignment and leadership in an EPP. Using ordered logistic regression and linear regression, the effects of the following leadership variables on the importance of alignment were analysed (Table 4, 5, 6, 7):

- Importance of leadership in the partnership process (Q11);

- $\quad$ Leadership perspective in partnerships (Q1 to 9);

- $\quad$ Relative importance of leadership, strategy and culture in partnerships (Q48);

- $\quad$ Typology of leadership (Figure 3).

The measured results suggested the following effects:

The importance of leadership (Q11) had significant positive effect. If the interviewees indicated leadership in the partnership to be important, they also judged alignment as important;

- The mutual background (Q4) had a significant negative effect. If the interviewees indicated that there was a 'mutual background,' then they recognised alignment as less important;

- The shared personal core values (Q5) only had a positive effect with ordered logistic regression. If the interviewees indicated that they considered 'shared personal core values' as important, then they found alignment important as well.

Table 4. Parameter estimates of ordered logistic regression and linear regression on the overall importance of alignment (Significant results at the $10 \%$ significance level are in bold)

\begin{tabular}{|c|c|c|c|c|}
\hline & \multicolumn{2}{|c|}{ Ordered logistic regression } & \multicolumn{2}{|l|}{ Linear regression } \\
\hline & $\begin{array}{l}\text { parameter (standard } \\
\text { error) }\end{array}$ & t-value & $\begin{array}{l}\text { parameter (standard } \\
\text { error) }\end{array}$ & p-value \\
\hline Q1. Importance of an instant connection / click & $\begin{array}{l}0.08 \\
(0.06)\end{array}$ & 1.34 & $\begin{array}{l}0.02 \\
(0.02)\end{array}$ & 0.30 \\
\hline Q3. Importance of a mutual background & $\begin{array}{l}0.03 \\
(0.08)\end{array}$ & 0.36 & $\begin{array}{l}0.00 \\
(0.02)\end{array}$ & 0.96 \\
\hline Q5. Importance of shared personal core values & $\begin{array}{l}\mathbf{0 . 1 1} \\
(0.05)\end{array}$ & 2.08 & $\begin{array}{l}0.02 \\
(0.01)\end{array}$ & 0.12 \\
\hline $\begin{array}{l}\text { Q7. Importance of mutual mission and vision on } \\
\text { civil society }\end{array}$ & $\begin{array}{l}-0.01 \\
(0.04)\end{array}$ & -0.23 & $\begin{array}{l}-0.01 \\
(0.01)\end{array}$ & 0.44 \\
\hline Q9. Importance of effects of prestige & $\begin{array}{l}0.04 \\
(0.06)\end{array}$ & 0.63 & $\begin{array}{l}0.01 \\
(0.02)\end{array}$ & 0.73 \\
\hline
\end{tabular}


Critical t-value with 10 degrees of freedom for $90 \%$ confidence interval: 1.81 .

Table 5. Parameter estimates of ordered logistic regression and linear regression on the overall importance of alignment (Significant results at the $10 \%$ significance level are in bold)

\begin{tabular}{|c|c|c|c|c|}
\hline & \multicolumn{2}{|c|}{ Ordered logistic regression } & \multicolumn{2}{|l|}{ Linear regression } \\
\hline & $\begin{array}{l}\text { parameter (standard } \\
\text { error) }\end{array}$ & t-value & $\begin{array}{l}\text { parameter (standard } \\
\text { error) }\end{array}$ & p-value \\
\hline $\begin{array}{l}\text { Q2. Was there an instant connection/click? } \quad(1= \\
\text { yes } / 0=\text { no })\end{array}$ & $\begin{array}{l}0.27 \\
(1.00)\end{array}$ & 0.27 & $\begin{array}{l}0.03 \\
(0.28)\end{array}$ & 0.92 \\
\hline Q4. Is there a mutual background? & $\begin{array}{l}\mathbf{- 2 . 8 4} \\
(1.36)\end{array}$ & -2.08 & $\begin{array}{l}\mathbf{- 0 . 6 8} \\
(0.34)\end{array}$ & 0.06 \\
\hline Q6. Are there shared personal core values? & $\begin{array}{l}0.48 \\
(1.08)\end{array}$ & 0.45 & $\begin{array}{l}0.08 \\
(0.28)\end{array}$ & 0.79 \\
\hline $\begin{array}{l}\text { Q8. Is there a mutual mission and vision on civil } \\
\text { society? }\end{array}$ & $\begin{array}{l}0.62 \\
(0.74)\end{array}$ & 0.83 & $\begin{array}{l}0.12 \\
(0.22)\end{array}$ & 0.59 \\
\hline Q10. Did in- or external prestige play a role? & $\begin{array}{l}0.50 \\
(0.53)\end{array}$ & 0.95 & $\begin{array}{l}0.10 \\
(0.14)\end{array}$ & 0.50 \\
\hline
\end{tabular}

Critical t-value with 10 degrees of freedom for $90 \%$ confidence interval: 1.81

Table 6. Parameter estimates of ordered logistic regression and linear regression on the overall importance of alignment (Significant results at the $10 \%$ significance level are in bold)

\begin{tabular}{|c|c|c|c|c|}
\hline & \multicolumn{2}{|c|}{ Ordered logistic regression } & \multicolumn{2}{|l|}{ Linear regression } \\
\hline & $\begin{array}{l}\text { parameter (standard } \\
\text { error) }\end{array}$ & t-value & $\begin{array}{l}\text { parameter (standard } \\
\text { error) }\end{array}$ & p-value \\
\hline \multirow[t]{2}{*}{ Q11. Importance of leadership in the partnership } & 0.21 & 2.60 & 0.03 & 0.04 \\
\hline & $(0.08)$ & & $(0.02)$ & \\
\hline \multirow[t]{2}{*}{ Q25. Importance of strategy in the partnership } & 0.08 & 1.60 & 0.01 & 0.40 \\
\hline & $(0.05)$ & & $(0.01)$ & \\
\hline \multirow[t]{2}{*}{ Q42. Importance of culture in the partnership } & 0.12 & 2.24 & 0.02 & 0.09 \\
\hline & $(0.05)$ & & $(0.01)$ & \\
\hline
\end{tabular}

Critical t-value with 12 degrees of freedom for $90 \%$ confidence interval: 1.78 .

Table 7. Parameter estimates of ordered logistic regression and linear regression on the overall importance of alignment (Significant results at the 10\% significance level are in bold.)

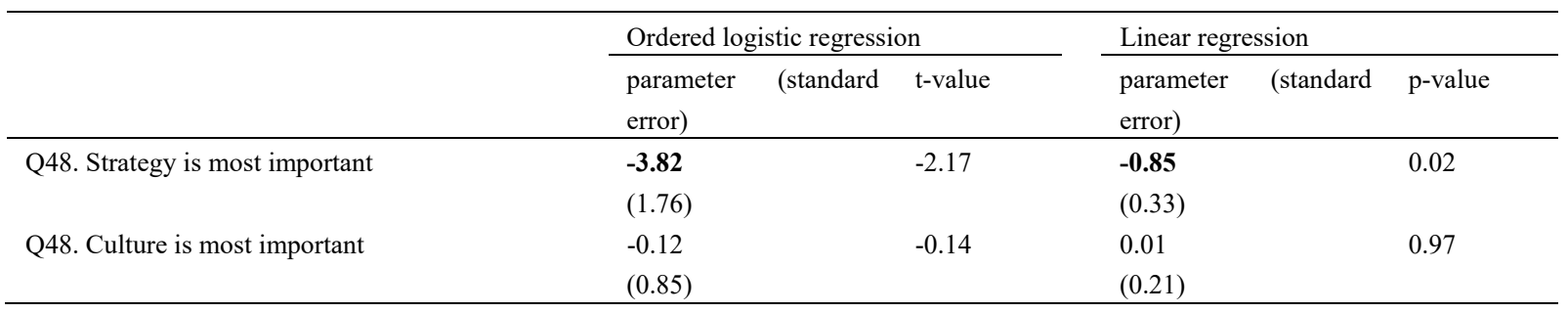

Critical t-value with 13 degrees of freedom for $90 \%$ confidence interval: 1.77 .

The results are relative to the base category in Q48 of choosing leadership as most important

Questions 4, 5 and 11 revealed an effect; therefore, hypothesis 4 was unable to be rejected. Managing the alignment process may be an important leadership function, as it begins with the PHs and SEs and cascades with patience through multi-tier alignments at succeeding staff levels. Alignment conserves a great amount of time and energy by confirming to all involved in the EPP process what they are supposed to be doing and why. This depends on both the rational and emotional buy-in to the mutual backgrounds of the parties involved. The result indicates that a mutual background may be a predictor of the importance of alignment in the partnership process. The various leadership typologies (Figure 3) did not influence the outcome, indicating that most interviewees were convinced that alignment is an integral part of the partnering process. EPPs seem to be complex entities; however, as with all relationships, they are vulnerable and subject to fallibility. When interviewees were asked to 
articulate their vision of these EPPs, their answers, in some ways, resembled a description of marriage: It requires a great number of shared values, trust and strong commitment in order to create and maintain a balanced, enduring partnership. It therefore appears crucial for potential partners to be as patient as possible with one another before signing off on a deal. EPPs have the potential to work only when the parties involved complement one another well, and all partners have something unique to bring to the table; something that enables them to build on and play off each other's strengths (Seitanidi \& Crane, 2008). When focusing on the societal impact, interviewees generally articulated a desire to motivate and encourage the partnership members to reach high levels of achievement; they approached the partnership with creativity and developed levels of understanding in the context of effective teamwork. The leadership was viewed as comprising alignment of two interrelated areas, strategy and culture which have a powerful effect on the motivation, self-confidence, self-efficacy, and performance, of others (Maximilian, 2006). PHs and SEs may identify the imperative of promoting greater cross-sector partnerships, or even direct that these should occur. They align people and events by what they say and do, and indirectly by implementing or modifying relevant programmes, systems and structures (Yukl, 2009). Fundamental to the partnership's development, in all contexts, is the ability of both the PH and the SE to fully engage staff members, and those with whom the EPP interacts. It was noticed that this research reinforced the view that leadership involves identifying, establishing, and maintaining beneficial relationships between the partnership organisation, on whom its accomplishment or defeat depends (Puth, 2002). However, PHs and SEs seemed unaware of their personal impact and judged themselves by their intentions and everyone else by their actions. Their leadership style provided an understandable link between leadership and EPP performance. It focused squarely on partnership impact, as opposed to personality or behaviour. When it came to reflecting on their own vision, values and ambition in civil society, they created a more empowering context for their EPP journeys and were more able to accomplish their own leadership potential (Alban-Metcalfe \& Alimo-Metcalfe, 2010). An EPP seems unsustainable with a fear-driven mindset since the PH and the SE may re-imagine what they are doing in a positive context in order to sustain energy and effort throughout the entire alignment process. It has previously been stated that the key ingredient for the EPP recipe is patience. Patience is a virtue that cannot be underestimated; it is the ability to wait calmly in the face of frustration or adversity. To be patient can significantly increases the impact of the EPP and it is vital in establishing compelling personal motivations for the envisaged partnership. The findings indicate that nothing guarantees EPP failure more than a lack of alignment among the partners. Conversely, when alignment does exist, the EPP leadership team will invest more of their time, talents and energy into meeting the formulated goals.

\subsection{Strategy, Alignment and Partnership}

The objective examined in this chapter was to establish a sound basis for the strategy of EPPs, to guide them by aligning the known strengths of the partners and to address areas where improvements are required to create a greater beneficial societal value. This objective led to the development of hypothesis 5: Alignment in entrepreneurial philanthropy varies according to what extent the strategy is guiding the partnership. With ordered logistic regression and linear regression, the effect of the following strategy variables was analysed regarding the importance of alignment (Table 6,7,8,9):

- Importance of strategy in the partnership process (Q25);

- $\quad$ Strategy perspective (Q15 to 24);

- $\quad$ Relative importance of leadership, strategy, and culture in partnerships (Q48);

- Type of strategy (Figure3).

The measured results indicate the following effects:

The importance of measuring (Q17) had a significant positive effect. If an interviewee considered it important to measure the (S)ROI, then she/he found alignment important;

The importance of an exit (Q20) had a significant positive effect. If an interviewee indicates that an opportunity for an exit had been formulated, then she/he found alignment more important;

The importance of the domains (Q48) had a significant positive effect. If an interviewee indicated 'strategy' to be the most important, he found alignment less important, compared to someone who considered 'leadership' or 'culture' to be the most important domain. 
Table 8. Parameter estimates of ordered logistic regression and linear regression on the overall importance of alignment (Significant results at the $10 \%$ significance level are in bold)

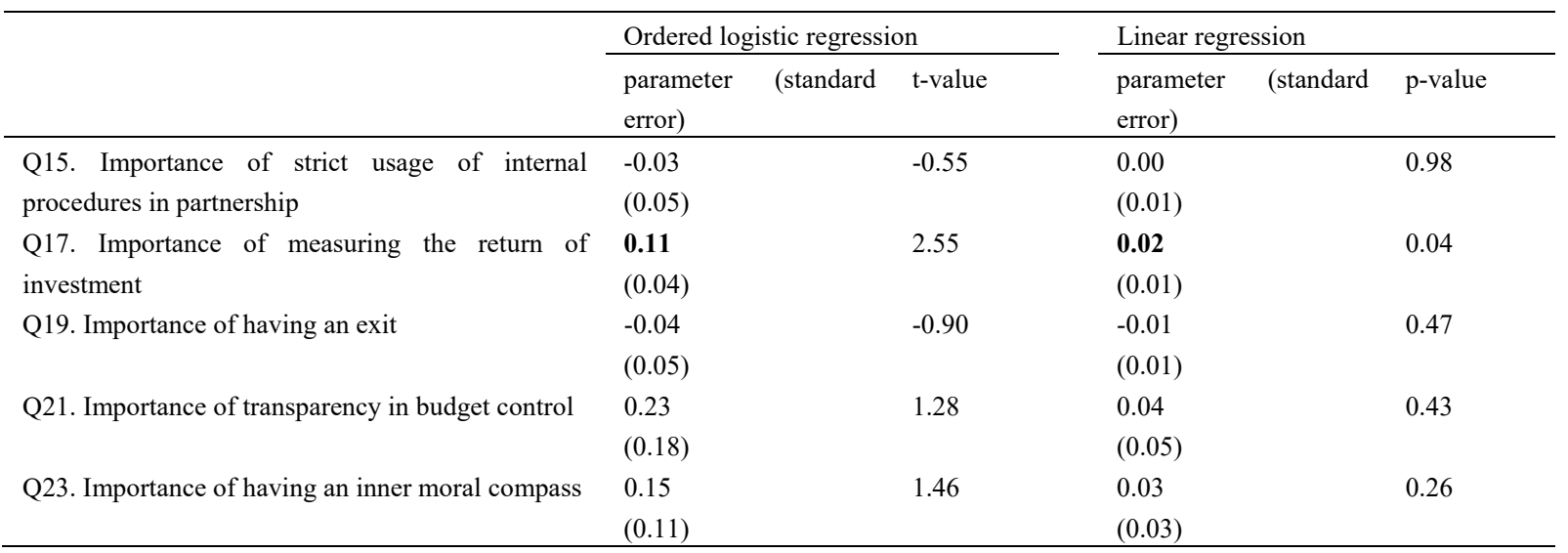

Critical t-value with 10 degrees of freedom for $90 \%$ confidence interval: 1.81 .

Table 9. Parameter estimates of ordered logistic regression and linear regression on the overall importance of alignment (Significant results at the $10 \%$ significance level are in bold.)

\begin{tabular}{|c|c|c|c|c|}
\hline & \multicolumn{2}{|c|}{ Ordered logistic regression } & \multicolumn{2}{|l|}{ Linear regression } \\
\hline & $\begin{array}{l}\text { parameter (standard } \\
\text { error) }\end{array}$ & t-value & $\begin{array}{l}\text { parameter (standard } \\
\text { error) }\end{array}$ & p-value \\
\hline $\begin{array}{l}\text { Q16. Are the formal internal procedures accurately } \\
\text { defined? }\end{array}$ & $\begin{array}{l}-0.41 \\
(1.08)\end{array}$ & -0.38 & $\begin{array}{l}-0.12 \\
(0.29)\end{array}$ & 0.68 \\
\hline $\begin{array}{l}\text { Q18. Are there procedures to measure the (social) } \\
\text { returns? }\end{array}$ & $\begin{array}{l}0.64 \\
(1.07)\end{array}$ & 0.60 & $\begin{array}{l}0.18 \\
(0.32)\end{array}$ & 0.59 \\
\hline Q20. Is the possibility of an exit formulated? & $\begin{array}{l}\mathbf{1 . 6 9} \\
(0.87)\end{array}$ & 1.94 & $\begin{array}{l}\mathbf{0 . 4 1} \\
(0.21)\end{array}$ & 0.07 \\
\hline $\begin{array}{l}\text { Q22. Is the process designed to achieve transparent } \\
\text { budget control? }\end{array}$ & $\begin{array}{l}-0.78 \\
(1.72)\end{array}$ & -0.45 & $\begin{array}{l}-0.18 \\
(0.56)\end{array}$ & 0.75 \\
\hline $\begin{array}{l}\text { Q24. Is there a guide for morally appropriate } \\
\text { behavior? }\end{array}$ & $\begin{array}{l}0.74 \\
(1.07)\end{array}$ & 0.69 & $\begin{array}{l}0.11 \\
(0.26)\end{array}$ & 0.67 \\
\hline
\end{tabular}

Critical t-value with 10 degrees of freedom for $90 \%$ confidence interval: 1.81

Questions 17, 20 and 48 supported hypothesis 5, which therefore was unable to be rejected. It has previously been suggested that both partners seek to gather information about the actual, or potential, societal impacts of the EPP. However, the interviewees stressed that this information is often difficult to collect, leaving the partners unable to track or express the value of their cooperation. Therefore, aligning the impact of the EPP requires a disproportionate amount of time, energy and investment from PHs and SEs. It has also been recognised, with some hesitation, that defining a graceful exit from the early beginning, well-matched to the characteristics of trust and respect of the partnership, would improve the probability of its success. As non-profits consistently emphasize the fulfilment of their mission, they must have the opportunity to apply for alternative partners in the future, to build capacity in order to achieve their long-term vision. Similarly entrepreneurial partners desire the option to end the EPP when the aimed for goals are not reached within the set time-frame. Although no formal blueprints exists for the process of alignment in the selected EPP strategy, research suggests that several indicators are useful in creating mutual understanding, such as the (S)ROI and the risk-taking concept. Consequently, mutual understanding about the scale of ambition is not an organic outcome; it is achieved purposefully, usually as the result of a company need or societal driver that prompts potential partners to take deliberate action to satisfy that need. From this perspective, the emergence of outcome-based funding is advancing the alignment of funding with shared strategic goals (Bugg-Levine \& Emerson, 2011). It has been stressed that the strategy process appears not to be linear and rigid, but rather flexible and repetitive, and there is considerable overlap between one stage and another (Sargeant \& Jay, 2014). Hence, personal and collective judgements seem crucial as an ongoing issue that stimulates multidirectional dialogue. This strategy is intended 
both to create awareness for those involved in the partnership work, and as a means of increasing its societal returns. It has been argued that the EPPs should not be seen as impediments to earnings, but as investments in a long-term development that can bring societal value to both the company and the non-profit with quality engagement and fully-galvanised contributions. However, a strategy does not always produce societal value, as partners may sometimes decide upon sub-optimal solutions, create new challenges, or not solve the initial problems (Bryson et al., 2006). Although the above-mentioned indicators provide guidance for the EPP, it has been indicated that there is a gap in the selected strategy with respect to understanding and communicating what constitutes alignment. Generally, the understanding and application of good EPP principles are based on an inclusive and strategic approach to accelerate purposeful action, engagement and delivery at global, regional or local levels. PHs and SEs without a partnership strategy are frequently at a disadvantage because they lack a framework to guide them in decision-making, which can greatly delay the process and is frustrating for potential partners. PHs seem dynamic in their strategy when creating EPPs with SEs, as they identify new motivations for societal investing and expect the EPP to produce measurable impact that resonate with their core values and mission; however, they must work toward gaining a shared understanding of the costs of achieving societal change. There appears to be agreement among the partners that a need exists to prioritize alignment with the strategy, and operationalising it into strategic objectives. However, PHs and SEs need to better align their EPP strategy to their own operational strategy, as the partnership builds alignment among and across stakeholders, initiatives, and interests. This alignment process seems to be the cornerstone: Bringing a range of partners together to focus on shared goals and objectives, amplifying the impact of the uniqueness of each partner. The EPP can create an internal dialogue and debate around evidence, challenges and policies related to the full continuum of care, and should encourage alignment of the broadest range of resources and initiatives to accelerate purposeful action. It has been noticed that this discourse depends on the capacity of staff at the various levels within the EPP to communicate the strategy that finally determines the degree of alignment in the organisation. Recognizing this critical value, the EPP can build structures and processes to strengthen the participation and influence of partners from all elements within the EPP in order to guide the strategy. This is interesting because it is a new opportunity to secure a better relationship between the members of the EPP.

\subsection{Culture, Alignment and Partnership}

The objective her was to create common ground for a mutually beneficial culture in the EPP, to supercharge it by aligning the strengths of the partners and to address areas in which improvements are required to create a greater beneficial impact on society. Hypothesis 6 was formulated as follows: Alignment in entrepreneurial philanthropy varies according to what extent the culture is supercharging the EPP. Using ordered logistic regression and linear regression, the effect of the following culture variables was analysed regarding the importance of alignment (Table 6, 7, 10, 11):

- $\quad$ Importance of culture in the EPP process $(\mathrm{Q} 42)$

- $\quad$ Culture perspective (Q30 to 41)

- $\quad$ Relative importance of leadership, strategy and culture in EPPs (Q48)

- $\quad$ Typology of culture (Figure 3)

The results from this study suggested the following effects of culture

- Knowledge sharing (Q39) had a significant positive effect. If an interviewee indicated that there was a 'sphere of influence along with individual knowledge', he found alignment more important;

- Understanding each other (Q40) had a significant positive effect. If an interviewee indicated 'gaining an understanding of each other' to be important, then she/he considered alignment to be important;

- The importance of culture (Q42) had a significant positive effect. If an interviewee considered culture in the partnership to be important, then she/he found alignment to be important. 
Table 10. Parameter estimates of ordered logistic regression and linear regression on the overall importance of alignment (Significant results at the $10 \%$ significance level are in bold)

\begin{tabular}{|c|c|c|c|c|}
\hline & \multicolumn{2}{|c|}{ Ordered logistic regression } & \multicolumn{2}{|l|}{ Linear regression } \\
\hline & $\begin{array}{l}\text { parameter (standard } \\
\text { error) }\end{array}$ & t-value & $\begin{array}{l}\text { parameter (standard } \\
\text { error) }\end{array}$ & p-value \\
\hline Q30. Importance of correlated management styles & $\begin{array}{l}-0.03 \\
(0.05)\end{array}$ & -0.59 & $\begin{array}{l}0.00 \\
(0.01)\end{array}$ & 0.92 \\
\hline $\begin{array}{l}\text { Q32. Importance of how prepared and able } \\
\text { employees are for change }\end{array}$ & $\begin{array}{l}0.07 \\
(0.09)\end{array}$ & 0.77 & $\begin{array}{l}0.00 \\
(0.02)\end{array}$ & 0.84 \\
\hline $\begin{array}{l}\text { Q34. Importance of stimulating the effort of } \\
\text { employees }\end{array}$ & $\begin{array}{l}-0.08 \\
(0.06)\end{array}$ & -1.27 & $\begin{array}{l}-0.01 \\
(0.01)\end{array}$ & 0.32 \\
\hline Q36. Importance of learning capacity of employees & $\begin{array}{l}0.08 \\
(0.09)\end{array}$ & 0.96 & $\begin{array}{l}0.02 \\
(0.02)\end{array}$ & 0.25 \\
\hline Q38. Importance of stimulating knowledge sharing & $\begin{array}{l}-0.10 \\
(0.07)\end{array}$ & -1.36 & $\begin{array}{l}-0.02 \\
(0.02)\end{array}$ & 0.32 \\
\hline $\begin{array}{l}\text { Q40. Importance of gaining an understanding of } \\
\text { each other }\end{array}$ & $\begin{array}{l}\mathbf{0 . 2 1} \\
(0.07)\end{array}$ & 2.93 & $\begin{array}{l}\mathbf{0 . 0 4} \\
(0.02)\end{array}$ & 0.01 \\
\hline
\end{tabular}

Critical t-value with 9 degrees of freedom for $90 \%$ confidence interval: 1.83 .

Table 11. Parameter estimates of ordered logistic regression and linear regression on the overall importance of alignment (Significant results at the $10 \%$ significance level are in bold)

\begin{tabular}{|c|c|c|c|c|}
\hline & \multicolumn{2}{|c|}{ Ordered logistic regression } & \multicolumn{2}{|l|}{ Linear regression } \\
\hline & $\begin{array}{l}\text { parameter (standard } \\
\text { error) }\end{array}$ & t-value & $\begin{array}{l}\text { parameter (standard } \\
\text { error) }\end{array}$ & p-value \\
\hline $\begin{array}{l}\text { Q31. Are there procedures to measure employee } \\
\text { satisfaction? }\end{array}$ & $\begin{array}{l}-1.44 \\
(1.23)\end{array}$ & -1.17 & $\begin{array}{l}-0.36 \\
(0.28)\end{array}$ & 0.22 \\
\hline $\begin{array}{l}\text { Q33. Is there a protocol to inform employees about } \\
\text { changes? }\end{array}$ & $\begin{array}{l}-1.26 \\
(1.12)\end{array}$ & -1.12 & $\begin{array}{l}-0.29 \\
(0.29)\end{array}$ & 0.32 \\
\hline Q35. Is there an employee engagement survey? & $\begin{array}{l}1.04 \\
(1.21)\end{array}$ & 0.86 & $\begin{array}{l}0.10 \\
(0.29)\end{array}$ & 0.74 \\
\hline $\begin{array}{l}\text { Q37. Is there a protocol to communicate about the } \\
\text { progress? }\end{array}$ & $\begin{array}{l}-1.46 \\
(1.19)\end{array}$ & -1.24 & $\begin{array}{l}-0.31 \\
(0.30)\end{array}$ & 0.33 \\
\hline $\begin{array}{l}\text { Q39. Is there a sphere of influence along with } \\
\text { individual knowledge? }\end{array}$ & $\begin{array}{l}3.02 \\
(1.04)\end{array}$ & 2.91 & $\begin{array}{l}\mathbf{0 . 6 3} \\
(0.22)\end{array}$ & 0.01 \\
\hline $\begin{array}{l}\text { Q41. Are misunderstanding and mistakes being } \\
\text { registered? }\end{array}$ & $\begin{array}{l}1.51 \\
(1.01)\end{array}$ & 1.50 & $\begin{array}{l}0.36 \\
(0.23)\end{array}$ & 0.15 \\
\hline
\end{tabular}

Critical t-value with 9 degrees of freedom for $90 \%$ confidence interval: 1.83 .

Questions 39, 40 and 42 support hypothesis 6, which therefore could not be rejected. It was noted that an EPP culture is built through shared learning and mutual experience, yet shaping the ideal culture can be a challenging task that requires a constant focus on alignment. In some EPPs the separate values must be translated into specific behaviours so that the cooperative behavioural norms can be reached, since aligned cultures tend to have a more engaged workforce. Sometimes interventions aimed at aligning the values and capabilities of the EPP are requirements necessary to continue the partnership. It is here argued when leading partners and their staff have the same view of the partnership culture, the employee engagement metrics (including satisfaction, commitment, and likelihood of recommending their organisations to others as a great place to work) are markedly higher than those in less aligned cultures. Ultimately, the true partnership culture will spring from the people and decisions that are being made, based on the aligned values (Celep et al., 2016). The objectives of an SE are generally driven by public service, and its primary goal is to leverage the resources available in order to deliver a societal purpose. The $\mathrm{PH}$, however, is not driven by the same primary goal, and its ultimate responsibility is to its shareholders; therefore, making a profit is the key consideration. Aligning a purpose culture with a profit culture is not always easily achievable. The challenge is in bringing the two cultures together in a way that it will result in a mutually beneficial relationship, which begins with strong leadership and engagement with the staff involved. The research indicated that when there is a delay in consummating a partnership, this may be for 
financial expectations or governance reasons; however, it may also be due to a difference in the cultures of the boards involved (Muller et al., 2014). In fact, understanding potentially conflicting cultures may be an influencing factor in closing and implementing EPPs. Effective EPPs depend on the establishment of adequate levels of trust and commitment between the non-profit and entrepreneurial partners in order for each partner to achieve complementary but different objectives (Sanzo et al., 2015). The success of these EPPs creates the paradigm of depending on the alignment of the organisations' cultures and it has been suggested, that potential partners should assess and take account of their organisational cultures before committing to partnership arrangements. Once the EPP has been finalised, successful implementation often depends on the entities' boards. The establishment of an EPP is not only linked to the cultural alignment of both organisations, but also to the $\mathrm{PH}$ and SE themselves. When people are working towards a common societal purpose built on the foundation of a mutual culture, and with systems and processes that are flexible and adaptive, EPPs may reach their full potential and achieve unprecedented levels of (S)ROI performance. EPPs that remain flexible are more likely to embrace change and create an environment that remains open to communication. This provides a model that welcomes cultural diversity and helps to clarify the alignment process. Culture is the self-sustaining patterns of behaviours and mindsets that determines how work gets done. It is here argued that culture plays a role in EPP-performance; however, most PHs and SEs may struggle to align culture with strategy and fully harness this power. Cultural alignment within an organisation can serve many purposes, including unifying members within an organisation and helping create a set of common norms or rules within an organisation that partners can follow (Bennett, et al., 2008). A stable culture, one that will systematically align leadership and strategy, will foster the culture of partnership, teamwork and cooperation among the staff. The responsibilities of the PH and SE create a clear reality of what the future of the EPP holds and assist in building the plans required to meet those realities. Therefore, in EPPs, the power of storytelling is suggested to be relevant both for the development of a mutual culture and for the ability to connect emotionally with the staff involved, since they are searching for context and meaning to navigate the intense challenges of the current landscape, not in mere facts and figures. When communicating for example the importance of taking risks, the staff will respond to a story about a risk the board took, how they failed and what they learned. This appears to be more powerful than simply hearing an senior executive of the board say, 'Take risks.' Storytelling was particularly mentioned, namely because it helps express the emotion behind a culture, as emotions may align human behaviour, more than can be achieved using common reason. In aligned partnerships, an emotionally engaging story develops that has relevance and meaning to every single member involved.

\subsection{Alignment and Partnership}

The objective here was to discover the effect of the phenomenon of alignment in the success of EPPs. Hypothesis 7 was derived as follows: The importance of the intermediating variable alignment explains the success of the EPP. The effect of alignment as an independent variables was analysed regarding its importance using ordered logistic regression and linear regression: The categories of 'excellent' and 'good' were achieved for question 49 (the rating of the partnership). As a consequence, the effect of alignment on the partnership was significant and the interpretation remained virtually identical. The outcomes of 'excellent' and 'good' both indicated a positive image held of the partnership (Table 12). The results indicated the following effects:

- The overall importance of alignment had a positive significant effect on the success of the EPP;

- If, according to an interviewee alignment was a more important factor in the establishment process of an EPP, then she/he gave the partnership a higher score.

Table 12. Parameter estimates of ordered logistic regression and linear regression on the overall rating of the partnership. (Significant results at the $10 \%$ significance level are in bold)

\begin{tabular}{|c|c|c|c|c|c|c|}
\hline & \multicolumn{3}{|c|}{ Ordered logistic regression } & \multicolumn{3}{|c|}{ Linear regression } \\
\hline & $\begin{array}{l}\text { parameter } \\
\text { error) }\end{array}$ & (standard & t-value & $\begin{array}{l}\text { parameter } \\
\text { error) }\end{array}$ & (standard & p-value \\
\hline Q49. Overall importance of alignment & $\begin{array}{l}\mathbf{2 . 0 5} \\
(1.08) \\
\end{array}$ & & 1.91 & $\begin{array}{l}\mathbf{0 . 6 0} \\
(0.30) \\
\end{array}$ & & 0.06 \\
\hline
\end{tabular}

Critical t-value with 14 degrees of freedom for $90 \%$ confidence interval: 1.76 .

The overall rating of the partnership (Q49) showed promise regarding identifying an effect; therefore hypothesis 7 could not be rejected. The insight gained about the concept of alignment when studying the success of EPP 
relates to the way in which PHs and SEs recognise the dynamics of their own organisation as well as that of their partner. This is best summarised by concluding that they may simultaneously create and respond to situations. In other words, rather than viewing each organisation as a separate, interdependent entity, it can be accepted that together they are providing different influences within the same civil society (Murphy, et al., 2014). Although an organisation may achieve alignment at a certain stage, the dynamic nature of EPPs makes this a moving target, which is therefore somewhat elusive. The primary task of PHs and SEs is that of consciously aligning the interdependencies between leadership, strategy, and culture, so the partnership will be more sustainable and operate at peak effectiveness. As a conceptual roadmap, alignment should be able to navigate the three domains, which together capture and explain the EPP. Alignment can be achieved with the help of a series of indicators that claim to objectively define the phenomenon as a set of given relationships, existing in themselves and capable of being grasped by both non-profits and companies. The civil society expects an increasing numbers of relationships between non-profits ad for-profits, and assumes those relationships to be engagement-focused, effective, transparent and to have their impact mirrored in the changes that occur (Eikenberry \& Kluver, 2004). These relationships are not solely based on financial transactions; a central role in these relationships are the two organisations working closely together to achieve mutual goals (Arenas, et al. 2013). Effective EPPs depend on establishing adequate levels of trust and commitment between the partner organisations and also between its leaders, for each of them to achieve complementary but differing objectives (Herlin, 2013). It has previously been reported that an alignment issue arises, shown by communication failures due to misunderstandings, when different types of organisations start cooperating. An universal language might be advantageous and is both the cause and the result of the alignment process. The success seems to depend on the alignment of the organisations' leadership, strategy and culture to create a strategic fit. It has been suggested, that potential partners should consider and assess this before committing to EPP arrangements. The alignment should also be secured, because securing it seems to have a transformative impact at a systems level. When EPP went beyond transactional and was instead transformative, a fundamental change in participation and engagement was noticed. As a result, EPPs are no longer 'things to do' but were an expression of 'who I am,' and became a long-term investment that may ultimately help both partners to succeed. It is here argued that a constant dialogue may reduce the risk of EPP failure by providing a structured, strategic approach to the partnering process . Sharing information about concrete resources such as financing, staffing, and training would illustrate a clear commitment to EPP within an organisation. It has been shown that such an alignment-seeking culture promotes identification of collaborative opportunities and communicates specific organisational values. Several successful partnering PHs and SEs position themselves as a partner-of-choice to promote new opportunities. This ensures their partnership portfolio includes a mix of organisations that are aligned with the strategic activities that best advances their own mission in civil society.

\section{Conclusion and Discussion}

Given the increasing proliferation of EPPs between PHs and SEs (Gordon et al., 2016, Taylor et al., 2014), the importance of understanding the indicators of relationship formation and its alignment cannot be understated. This study was designed to determine whether or not a theoretical EPAM has the ability to explore the dynamics of the non-profit and for-profit partnership process by testing a number of key indicators derived from the domains of leadership, strategy, and culture and its hypothetical effects on alignment in EPPs. Preliminary evidence can be drawn from the discussions in this paper and it is aimed that the findings will give the PHs and SEs involved, more guidance on conditions that might encourage (or impede) the concept of an EPP. First, analysis results revealed that the indicators of leadership and culture are more related with establishing an EPP than the indicators of strategy, but only partial conformation was provided for the prediction that the selected indicators of the three domains have a positive correlation therefore, further weighting of selected indicators is probably needed (Hypothesis 1, 2 and 3). Second, the results provided conformation for the prediction that leadership has a positive correlation with the process of alignment (Hypothesis 4). Third, alignment is indeed varying to what extent the culture is supercharging the partnership, while strategy is responding in a similar way when guiding the partnership (Hypothesis 5 and 6). Fourth, the data collected provide support that the importance of alignment might explain the dynamic process of establishing an EPP (Hypothesis 7). Overall there was sufficient evidence to answer the research questions positively. Therefore, the EPAM suggest to be able to support research informed practitioners, to make more explicit the interrelationships across the components of an EPP, by analysing the answers to the following questions: (a) Is there alignment in the leadership of both partners? (b) Is there alignment of each other's culture? (c) Is there potential partner 'fit' regarding the defined partnership objectives? (d) What impact will be realised by the EPP and will benefit which organisations, individuals, and/or for the civil society in general? 
On a more conceptual level, the selected indicators and the associations with alignment presented in this paper can be used to identify preferred patterns of leadership, strategy and culture to establish EPPs. The study has indicated a causation on the level of the three domains and verified that focusing on the alignment will contribute to a better understanding of the EPP processes involved. The recognition that leadership and culture are paramount in determining EPP outcomes has also implications for the cooperation especially since the selected strategy is more seen as an iterative process rather than a straight line, where decisions are not easily revocable. Against this background, the demonstrated level of importance with indicators of the the EPAM (Figure 4) would give both partners a better choice of possible outcomes and stimulates creativity that implies to be relevant in deciding how to proceed in the EPP planning process. The EPAM is helping to generate and evaluate concrete outcomes, align plans with realistic implementation of timeframes and budgets, and empower teams and cultures to accomplish EPP goals.

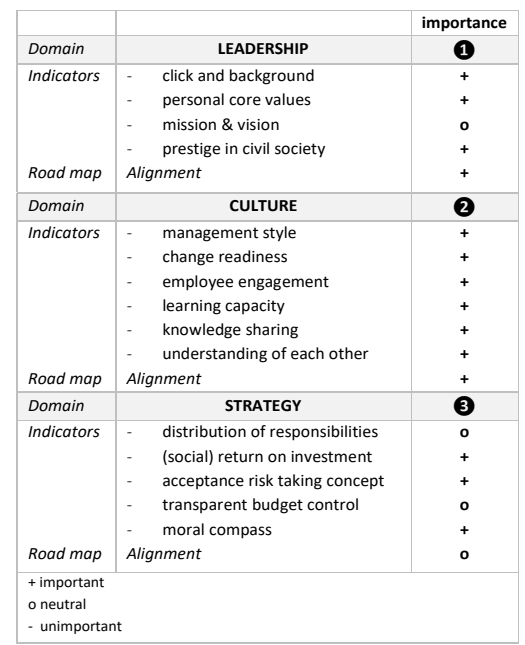

Figure 4. Importance of the EPAM indicators and alignment on EPPs

Ultimately, this study may confirm that in EPPs, SEs require to focus on their leadership to evaluate contemporary business approaches, create a strong partnership culture with their staff, and invest in understanding each other's organisation to accelerates societal impact. The involved PHs contiguous also need an intentional focus on their social-cognitive leadership attributes, to set the non-profit sector on a path towards financial value creation and societal impact; however, they can enhance their understanding of the way how they can support non-profits, with the ultimate goal of improving the philanthropic services introduced (Shang \& Sargeant, 2017). PHs and SEs regularly stated how an unproductive culture can get in the way of what their partnership have the capacity and the potential to achieve. Although practice and theory seem to indicate that focussing on the dynamic strivings for alignment is beneficial for both partners, the societal impact measurement of an EPP is still looking for an appropriate metrics system that monitors the output and outcome, in order to help the partners to find the right balance for their input. Thereby, an understanding of the phenomenon of alignment and a mutual commitment to it, has the appearance of being necessary for developing an EPP, which consumes always substantially more time than was originally expected. Perhaps the most interesting general finding of this study is that 'patience' seems to be a conditio sine qua non for the establishment of an EPP, but it has been noted that patience without strong relational leadership or constructive partnership culture can harm the partnership establishment process severely.

A growing amount of philanthropic societal achievement has the potential ability to be produced in EPPs (Seitanidi \& Crane, 2013). Theoretical research of these partnership agreements has given an initial understanding of the importance of the initial interpersonal 'click' to identify partners that share ambitions and values, the leadership required to ultimately create societal impact, and the many positive effects of a mutual partnership culture. The data analysed in the qualitative test delivered preliminary evidence that the concept of the EPAM may be effective for EPP formation and cooperation, by developing the required alignment as its effective road map. What follows is a synthesis of fundamental cross-cutting themes that reveals a pathway of practice and expertise PHs and SEs may want to emulate. Notwithstanding the above mentioned points, there are lacunas within the process of alignment to EPPs that call for clarification. Further research is needed to adjust the 
practice-based indicators with more overarching theoretical EPP alignment concepts. Nevertheless, this study yield several promising directions for future research on EPPs.

\section{References}

Alban-Metcalfe, J., \& Alimo-Metcalfe, B. (2010). Integrative leadership, partnership working and wicked problems: A conceptual analysis. International Journal of Leadership in Public Services, 6(3), 3-13. https://doi.org/10.5042/ijlps.2010.0512

Arenas, D., Sanchez, P., \& Murphy, M (2013). Different Paths to Collaboration Between Businesses and Civil Society and the Role of Third Parties. Journal of Business Ethics, 115(4), 723-739. https://doi.org/10.1007/s10551-013-1829-5

Austin, J. E., \& Seitanidi M. M. (2012). Collaborative Value Creation: A Review of Partnering Between Nonprofits and Businesses. Part 2: Partnership Processes and Outcomes. Nonprofit and Voluntary Sector Quarterly, 41(6), 929-968. https://doi.org/10.1177/0899764012454685

Austin, J. E., \& Seitanidi, M. M. (2014). Creating Value in Nonprofit-Business Collaborations: New Thinking and Practice. San Francisco: Jossey-Bass.

Babiak, K., \& Thibault, L. (2007). Challenges in Multiple Cross-Sector Partnerships. Nonprofit and Voluntary Sector Quarterly, 38(1), 117-143. https://doi.org/10.1177/0899764008316054

Bennett, R., Mousley, W., \& Ali-Choudhury, R. (2008). Transfer of Marketing Knowledge within Business-Nonprofit Collaborations. Journal of Nonprofit \& Public Sector Marketing, 20(1), 37-70. https://doi.org/10.1080/10495140802165352

Berger, L. E., Gunningham, P. H., \& Drumwright M. E. (2004). Social Alliances: Company/Nonprofit Collaboration. California Management Review 47(1), 58-90.

Bryson, J. M., Crosby, B. C., \& Middleton Stone, M. (2006). The design and implementation of cross-sector collaborations; Propositions from the literature. Public Administration Review, 66, 44-55.

Bugg-Levine, A., \& Emerson, J. (2011). Impact Investing: Transforming How We Make Money While Making a Difference. San Francisco: Jossey-Bass.

Celep, A., Brenner, S., \& Mosher-Williams, R. (2016). Internal Culture, External Impact: How a Change-Making Culture Positions Foundations to Achieve Transformational Change. The Foundation Review, 8(1), 116-129. https://doi.org/10.9707/1944-5660.1288

Connor, M.L., \& Clawson, J.G. (Eds.). (2004). Creating a Learning Culture: Strategy, Technology, and Practice. Cambridge, UK: Cambridge University Press.

Day, D. V., \& Antonakis, J. (2012). Leadership: Past, present, and future. The Nature of Leadership, 2, 393-436.

Dees, J.G. (1998). Enterprising Nonprofits. Harvard Business Review, 76(1), 54-67.

Demetriou, M., Papasolomou, I., \& Vrontis, D. J. (2010). Cause-related marketing: Building the corporate image while supporting worthwhile causes. Journal of Brand Management, 17(4), 266-278. https://doi.org/10.1057/bm.2009.9

Drucker, P.F. (2006). Managing the Non-profit Organization: Practices and Principles. New York: HarperCollins.

Eikenberry, A. M., \& Kluver, J. D. (2004). The Marketization of the Nonprofit Sector: Civil Society at Risk? Public Administration Review, 64(2), 32-140. https://doi.org/10.1111/j.1540-6210.2004.00355.x

Gonzalez, M. (2001). Strategic Alliances: The Right Way to Compete in the 21st Century. Ivey Business Journal, $66(1), 47-51$.

Gordon, J., Harvey, C., Shaw, E., \& Maclean, M. (2016). Entrepreneurial philanthropy. London, UK: Routledge.

Handy, C. (1993). Understanding organizations. UK, Penguin.

Hayes, A.F., \& Montoya, A.K. (2017). A Tutorial on Testing, Visualizing, and Probing an Interaction Involving a Multicategorical Variable in Linear Regression Analysis. Journal Communication Methods and Measures, 11(1), 1-30. https://doi.org/10.1080/19312458.2016.1271116

Herlin, H. (2013). Better Safe Than Sorry. Nonprofit Organizational Legitimacy and Cross-Sector Partnerships. Business \& Society, 54(6), 822-858. https://doi.org/10.1177/0007650312472609

Kahneman, D., \& Klein, G. (2009). Conditions for intuitive expertise: A failure to disagree. American 
Psychologist, 64(6), 515-526. https://doi.org/10.1037/a0016755

Kaplan, R. S., \& Norton, D. P. (2006). Alignment: Using the Balanced Scorecard to Create Corporate Synergies. Boston: Harvard Business School Publishing Corporation.

Maclean, M., Harvey, C., \& Gordon, J. (2012). Social innovation, social entrepreneurship and the practice of contemporary entrepreneurial philanthropy. International Small Business Journal, 31(7), 747-763. https://doi.org/10.1177/0266242612443376

Maximilian, M. (2006). Philanthropy's Leadership Challenge. Viewpoints, 10-16. Retrieved from https://ssrn.com/abstract $=1322271$

Mintzberg, H. (1987). The Strategy Concept I: Five Ps for Strategy. California Management Review, 30(1), 11-24. https://doi.org/10.2307/41165263

Mitchell, K., \& Sparke, M. (2016). The New Washington Consensus: Millennial Philanthropy and the Making of Global Market Subjects. Antipode, 48(3), 724-749. https://doi.org/10.1111/anti.12203

Mohr, J., \& Spekman, R. (1994). Characteristics of Partnership Success: Partnership Attributes, Communication Behavior, and Conflict Resolution Techniques. Strategic Management Journal, 15(2), 135-152.

Mood, C. (2010). Logistic Regression: Why We Cannot Do What We Think We Can Do, and What We Can Do About It. European Sociological Review, 26(1), 67-82. https://doi.org/10.1093/esr/jcp006

Muller, A. R., Pfarrer, M. D., \&Little, M. L. (2014). A Theory of Collective Empathy in Corporate Philanthropy Decisions. Academy of Management Review, 39(1), 1-21. https://doi.org/10.5465/amr.2012.0031

Murphy, D. F., \& Bendell, J. (1999). Partners in time? Business, NGOs and sustainable development. UNRISD Discussion Paper 109. http://www.unrisd.org

Murphy, M., Arenas, D., \& Batista, J. M. (2014). Value Creation in Cross-Sector Collaborations: The Roles of Experience and Alignment. Journal of Business Ethics, 130(1), 145-162. https://doi.org/10.1007/s10551-014-2204-x

Oliver, C. (1990). Determinants of interorganizational relationships: Integration and future directions. Academy of Management Review, 15(2), 241-265. https://doi.org/10.5465/AMR.1990.4308156

Parmenter, D. (2010). Key Performance Indicators: Developing, Implementing, and Using Winning KPIs. Hoboken: John Wiley \& Sons.

Patton, M. Q., Foote, N., \& Radner, J. (2015). A Foundation's Theory of Philanthropy: What It Is, What It Provides, How to Do It. The Foundation Review, 7(4), 6-20. https://doi.org/10.9707/1944-5660.1263

Porter, M. E., \& Kramer M. R. (2006). Strategy \& Society: The Link Between Competitive Advantage and Corporate Social Responsibility. Harvard Business Review, 84(12), 78-92.

Puth, G. (2002). The Communicating Leader: the Key to Strategic Alignment. Pretoria: Van Schaik.

Rath, J. H., \& Schuyt, T. N. M. (2014). Entrepreneurial Philanthropy: an Exploratory Review. Journal of Wealth Management, 17(3), 35-46. https://doi.org/10.3905/jwm.2014.17.3.035

Rath, J. H., \& Schuyt, T. N. M. (2015). Entrepreneurial Philanthropy Meet with Non-Profits: In Search of Alignment. Journal of Economic Behavior and Organization, 3(4), 55-64. https://doi.org/10.11648/j.ijebo.20150304.11

Rath, J. H., \& Schuyt, T. N. M. (2015). From Philanthropy to Partnerships: Testing a Theoretical Framework of Entrepreneurial Philanthropy Alignment. Journal of Service Science and Management, 8(3), 425-442. https://doi.org/10.4236/jssm.2015.83044

Rath, J. H., \& Schuyt, T. N. M. (2017). Bridging the Gap: Development of the Entrepreneurial Philanthropy Alignment Model. Journal of Marketing Studies, 9(2), 1-11. https://doi.org/10.5539/ijms.v9n2p1

Rumsey, G. G., \& White, C. (2009). Strategic corporate philanthropic relationships: Nonprofits' perceptions of benefits and corporate motives. Public Relations Review, 35(3), 301-303. https://doi.org/10.1016/j.pubrev.2009.05.005

Sanzo, M. J., Alvarez, L. I., Rey, M., \& Gracia, N. (2015). Business-nonprofit partnerships: A new form of collaboration in a corporate responsibility and social innovation context. Service Business, 9(4), 611-636. https://doi.org/10.1007/s11628-014-0242-1

Sargeant, A., \& Jay, E. (2014). Fundraising Management: Analysis, Planning and Practice. London, UK: 
Routledge.

Saunders, M. N., Lewis, P., \& Thornhill A. (2000). Research Methods for Business Students (2nd ed.). London: Prentice Hall.

Schein, E. H. (2010). Organizational culture and leadership (Vol. 2). San Francisco: John Wiley \& Sons.

Seitanidi, M. M., \& Crane, A. (2008). Implementing CSR Through Partnerships: Understanding the Selection, Design and Institutionalisation of Nonprofit-Business Partnerships. Journal of Business Ethics, 85(2), 413-429. https://doi.org/10.1007/s10551-008-9743-y

Seitanidi, M. M., \& Crane, A. (Eds.). (2013). Social partnerships and responsible business: A research handbook. London, UK: Routledge.

Shang, J., \& Sargeant, A. (2017). Insights into the Future of Philanthropic Innovation: Philanthropic Literacy for Future Leaders. Plymouth, UK: The Resource Alliance and Plymouth University

Shaw, E., Gordon, J., Harvey, C., \& Maclean, M. (2013). Exploring contemporary entrepreneurial philanthropy. International Small Business Journal, 31(5), 580-599. https://doi.org/10.1177/0266242611429164

Siltaoja, M. E. (2006). Value Priorities as Combining Core Factors Between CSR and Reputation - A Qualitative Study. Journal of Business Ethics, 68(1) 91-111. https://doi.org/10.1007/s10551-006-9042-4

Stadtler, L. (2011). Aligning a Company's Economic and Social Interests in Cross-Sector Partnerships. The Journal of Corporate Citizenship, 44, 85-106.

Stigler, S. (2008). Fisher and the 5\% level. Chance, 21(4), 12. http://dx.doi:10.1007/s00144-008-0033-3

Suen, W. (2005). Non-Cooperation - The Dark Side of Strategic Alliances. Hampshire: Palgrave Macmillan. https://doi.org/10.1057/9780230596573

Taylor, M. L., Strom, R. J., \& Renz, D. O. (Eds.). (2014). Handbook of Research on Entrepreneurs Engagement in Philanthropy: Perspectives. Cheltenham, UK: Edward Elgar Publishing.

Trevisani, D. (2016). Communication for Leadership: Coaching Leadership Skills. Ferrara: Medialab Research.

Vicere, A.A. (2010). The Real Legacy of Leadership: Aligning Rhetoric with Reality. In Goldsmith, M., Baldoni, J., \& McArthur, S. (Eds.), The Handbook of Leadership. New York: AMA.

Weiss, E. S., Miller Anderson, R., \& Lasker, R. D. (2002). Making the Most of Collaboration: Exploring the Relationship between Partnership Synergy and Partnership Functioning. Health Education \& Behavior, 29(6), 683-698.

Young, D. R. (2000). Alternative models of government-nonprofit sector relations: Theoretical and international perspectives. Nonprofit and Voluntary Sector Quarterly, 29(1), 149-172.

Yukl, G. (2009). Leading organizational learning: reflections on theory and research. Leadership Quarterly, 20, 49-53.

\section{Copyrights}

Copyright for this article is retained by the author(s), with first publication rights granted to the journal.

This is an open-access article distributed under the terms and conditions of the Creative Commons Attribution license (http://creativecommons.org/licenses/by/4.0/). 